\title{
Predictors of left atrial thrombus in acute ischemic stroke patients without atrial fibrillation: A single-center cross-sectional study
}

\author{
DTufan Cinar ${ }^{1}$ \\ (D) Mert ilker Hayiroğlu' \\ (iD) Vedat Çiçek ${ }^{1}$ \\ (iD) Süha Asal' \\ (D) Murat Mert Atmaca² \\ (iD) Nurgül Keser ${ }^{1}$ \\ DAhmet Lütfullah Orhan'
}

1. Health Science University, Sultan Abdulhamid Han Training and Research Hospital, Department of Cardiology, Istanbul, Turkey 2. Health Science University, Sultan Abdulhamid Han Training and Research Hospital, Department of Neurology, Istanbul, Turkey

http://dx.doi.org/10.1590/1806-9282.66.10.1437

\section{SUMMARY}

INTRODUCTION: The present study aimed to determine independent predictors of left atrial thrombus (LAT) in acute ischemic stroke (AIS) patients without atrial fibrillation (AF) using transesophageal echocardiography (TEE).

METHODS: In this single-center, retrospective study, we enrolled 149 consecutive AIS patients. All of the patients underwent a TEE examination to detect LAT within 10 days following admission. Multivariate logistic regression analysis was performed to assess independent predictors of LAT.

RESULTS: Among all cases, 14 patients (9.3\%) had a diagnosis of LAT based on the TEE examination. In a multivariate analysis, elevated mean platelet volume (MPV), low left-ventricle ejection fraction (EF), creatinine, and reduced left-atrium appendix (LAA) peak emptying velocity were independent predictors of LAT. The area under the receiver operating characteristic curve analysis for MPV was 0.70 ( $95 \% \mathrm{Cl}$ : 0.57-0.83; $p=0.011$. With the optimal cut-off value of 9.45, MPV had a sensitivity of $71.4 \%$ and a specificity of $63 \%$ to predict LAT.

CONCLUSION: AIS patients with low ventricle EF and elevated MPV should undergo further TEE examination to verify the possibility of a cardio-embolic source. In addition, this research may provide novel information with respect to the applicability of MPV to predict LAT in such patients without AF.

KEYWORDS: Stroke. Heart atria. Thrombosis. Mean platelet volume.

\section{INTRODUCTION}

Stroke is a leading cause of morbidity and disability in both developed and developing countries and is the second most common cause of death worldwide'. Acute ischemic stroke (AIS) accounts for approximately $85 \%$ of all cases and can be classified into five main subtypes based on their etiopathogeneses: I) small vessel occlusion (lacunar infarction), II) large artery atherosclerosis (atherothrombotic),

DATE OF SUBMISSION: 17-Mar-2020

DATE OF ACCEPTANCE: $21-A p r-2020$

CORRESPONDING AUTHOR: Tufan Cinar

Heath Science University, Sultan Abdulhamid Han Training and Research Hospital, Tibbiye Street, Uskudar, Istanbul, Turkey

Tel: +90-216-542-2020 - Fax: +90-216-542-2010

E-mail:drtufancinar@gmail.com 
III) cardio-embolism, IV) stroke of other determined etiology, and V) stroke of undetermined etiology ${ }^{2}$. In particular, patients with cardio-embolic stroke usually have high mortality, disability, and poor neurological outcomes compared to the other types of ischemic stroke $^{3}$. Although previous studies have demonstrated that atrial fibrillation $(\mathrm{AF})$ is the most common source of cardio-embolism due to the formation of left atrial thrombi (LAT) ${ }^{3}$. The data regarding predictors of LAT in AIS patients without AF is not clearly defined in the current literature.

In current practice, transthoracic echocardiography (TTE) is the initial imaging modality in patients with AIS ${ }^{4}$. However, it is not usually possible to exclude all causes of cardio-embolism using TTE alone. In addition, there is no strong recommendation in the current guideline on whether patients with normal TTE findings must undergo further transesophageal echocardiography (TEE) examination to verify potential sources of cardio-embolism in AIS patients with undetermined etiology ${ }^{4}$. Besides that, because TEE is a semi-invasive procedure and carries some risk of complications in patients with recent ischemic stroke, identifying the patients who will most benefit from this examination would be useful in clinical practice.

In light of these data, the present study aimed to determine predictors of LAT that were not detected on TTE but confirmed only using TEE in AIS patients without AF.

\section{METHODS}

\section{Patient selection}

In this single-center, retrospective, and cross-sectional study, we enrolled 149 consecutive AIS patients who had undergone a TEE examination with a preliminary diagnosis of cardio-embolic source in a tertiary center. Patients who had AF (paroxysmal or persistent) and stroke of other identifiable etiology were excluded from the study. Also, 2 patients who were diagnosed with left-ventricle thrombosis and 4 patients with right-atrial thrombosis were not included in the study. In all of the patients, cranial magnetic resonance imaging, including diffusion-weighted imaging and T2-weighted imaging, was used to confirm the diagnosis of AIS or transient ischemic attack (TIA). In order to rule out a stroke of atherothrombotic sources, either magnetic resonance angiography or computed tomography angiography was ordered in all patients. Per hospital protocol, all patients with signs and symptoms of stroke were evaluated by an experienced neurologist following admission. A 24-72h Holter monitoring was routinely applied to all the patients to rule out any possible arrhythmias, including AF. The clinical data of all patients were collected from the hospital electronic database. The independent local ethics committee approved the design of the present study (approval number: HNEAH/KAEK/2019/KK/171), which was conducted in accordance with the "Good Clinical Practice" guidelines of the Declaration of Helsinki.

\section{TEE examination}

After overnight fasting of $8 \mathrm{~h}$, all of the patients underwent TEE examination to detect LAT 10 days after admission. Informed consent was obtained from all patients or patients' relatives to perform the TEE examination. All TEE procedures were performed by two experienced echocardiographers in the left lateral decubitus position. In all patients, a local anesthetic was given to anesthetize the oropharynx. If indicated, intravenous diazepam was given for sedation. Images were obtained using an iE33 ultrasound system with a multiplane $5 \mathrm{MHz}$ probe (Philips Med. Sys., Massachusetts, USA). On the TEE examination, the left atrium (LA) and left atrium appendix (LAA) were assessed in different planes to determine the presence of LAT. We evaluated the LAA flow velocities by placing a pulsed Doppler from the beginning of the LAA to the body of the LA. Figure 1 displays a case of AIS patient with a thrombus found in the LAA.

\section{Laboratory analysis}

All blood samples were collected on admission before TEE examination. Hematologic parameters, including hemoglobin, white blood cell, and platelet counts were measured as a part of the automated complete blood count, using the Sysmex XN 9000 hematology analyzers (Sysmex Corporation, Kobe, Japan). Biochemical measurements were performed using Beckman Coulter, Inc. kits and calibrators. The normal range for the mean platelet volume (MPV) in our institution was between 7 and $11 \mathrm{fL}$.

\section{Definitions}

Cranial infarction was accepted as an acute neurological incident continuing $\geq 24 \mathrm{~h}^{5}$. TIA was defined as an abrupt onset of neurological events or amaurosis fugax lasting $<24 \mathrm{~h}^{5}$. LAT was defined as a circumscribed homogenous mass attaching to the LA wall or LAA which was seen in at least two different degrees 


\section{FIGURE 1}

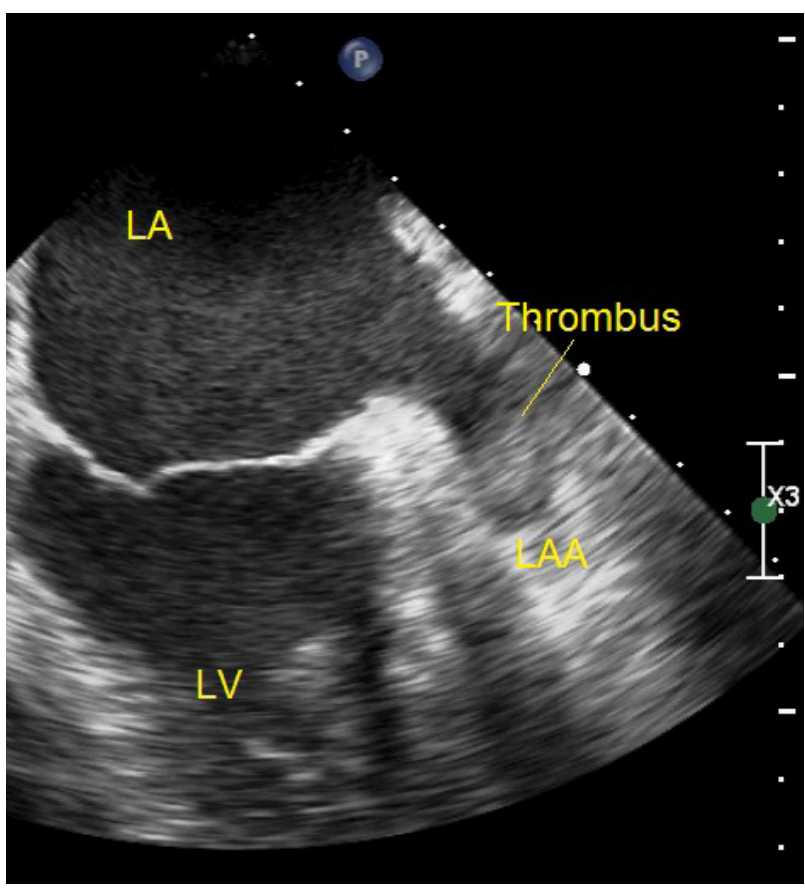

of mobility and echogenicity compared to myocardial texture. LA spontaneous echo contrast (SCE) was graded from I to III. Patent foramen ovale (PFO) was confirmed if microbubbles were spontaneously seen in the LA or after performing the Valsalva maneuver.

\section{Statistical analysis}

All statistical analyses were done using SPSS software, IBM, version 21.0. To test if the variables were normally distributed, the Kolmogorov-Smirnov test was performed. For continuous parameters, the data were presented as mean \pm standard deviation or median, while the data were provided as percentage and number values for categorical parameters. To determine the difference between the groups of continuous parameters with normal distribution, the independent $t$-test was performed. The Mann-Whitney U-test was used in the analysis of continuous parameters without normal distribution. For categorical variables, the Chi-square test was used. In order to determine the predictors of LAT, we first performed univariate analysis. The variables with a significance of $p<0.05$ were used in the multivariate analysis. After that, the multivariate logistic regression analysis was used to assess independent predictors of LAT. Calibration was assessed using the Hosmer-Lemeshow goodness-of-fit test and was satisfied when the p-value was $>0.05$. The Hosmer-Lemeshow statistic of multivariate analysis did not suggest a lack of fit $(\chi 2=13.818, p=0.087)$. The effect size (Cohen's $d)$ and power value (1- $\beta$ ) were calculated using $G^{*}$ Power software (version 3.1.9.2.). The effect size and power value were 0.86 and 0.97 , respectively. The optimal cut-off value of MPV for LAT was evaluated using the receiver operating curve (ROC) analysis. A p-value <0.05 was considered statistically significant.

\section{RESULTS}

In the present study, the mean age was $64 \pm 13$ years and 76 (51\%) of the patients were male. Among all patients, $14(9.3 \%)$ had a diagnosis of LAT on the TEE examination. We classified the study cohort into two groups: Patients with thrombus $(+)$ and without thrombus (-).

The baseline clinical features of all patients are displayed in Table 1. The study results show that patients who had LAT had an older age and higher prevalence of diabetes. No significant differences in terms of other baseline clinical features were found between the groups. We observed that 5 patients (3.7\%) without LAT (3 patients with grade III, 1 patient with grade II, and 1 patient with grade I) and 5 patients (35.7\%) with LAT (2 patients with grade III, 3 patients with grade II) had SCE on the TEE examination.

Laboratory and echocardiographic findings of the study population are depicted in Table 2 . Red blood cell distribution width, MPV, creatinine, and blood urea nitrogen (BUN) levels were significantly elevated in patients with LAT. In terms of echocardiographic parameters, patients with LAT had lower left-ventricle ejection fraction (EF) and LAA peak emptying velocity. We found that the frequency of tricuspid regurgitation was significantly higher in cases with LAT. In comparison, the other echocardiographic parameters were not different between the groups.

The independent predictors of LAT were identified using univariate and multivariate logistic regression analysis as shown in Table 3. A logistic regression analysis using the backward LR method was done for multivariate analysis of the variables that were found significant in the univariate analyses $(p<0.05)$. According to the multivariate analysis, elevated MPV, low ventricle EF, creatinine, and a reduced LAA peak emptying velocity were independent predictors of LAT.

The optimal value of MPV to predict LAT revealed by ROC analysis is shown in Figure 2. The area of MPV under the ROC analysis was 0.70 (95\%CI: 0.57-0.83; p $=0.011$ ). With the optimal cut-off value of $9.45, \mathrm{MPV}$ 
TABLE 1. COMPARISON OF DEMOGRAPHIC AND CLINICAL CHARACTERISTICS OF PATIENTS ACCORDING TO THE PRESENCE OF THROMBUS

\begin{tabular}{|c|c|c|c|}
\hline & $\begin{array}{l}\text { Thrombus } \\
(-) \\
(n=135)\end{array}$ & $\begin{array}{l}\text { Thrombus } \\
(+) \\
(n=14)\end{array}$ & $\begin{array}{l}P \\
\text { value }\end{array}$ \\
\hline Age, y & $\begin{array}{l}57.7 \\
(46.0-72.0)\end{array}$ & $\begin{array}{l}72.2 \\
(66.0-82.0)\end{array}$ & 0.007 \\
\hline Male gender, n (\%) & $68(50.4)$ & $8(57.1)$ & 0.629 \\
\hline Hypertension, n (\%) & $31(23.0)$ & $5(35.7)$ & 0.327 \\
\hline Diabetes mellitus, n (\%) & $78(57.8)$ & $12(85.7)$ & 0.030 \\
\hline Hyperlipidemia, n (\%) & $36(26.7)$ & $3(21.4)$ & 1.000 \\
\hline Smoking, n (\%) & $20(14.8)$ & $2(14.3)$ & 1.000 \\
\hline $\mathrm{PCl}, \mathrm{n}(\%)$ & $41(30.4)$ & $6(42.9)$ & 0.372 \\
\hline CABG, n (\%) & $12(8.9)$ & $1(7.1)$ & 1.000 \\
\hline CVA, n (\%) & $16(11.9)$ & $4(28.6)$ & 0.097 \\
\hline CRF, n (\%) & $65(48.1)$ & $9(64.3)$ & 0.247 \\
\hline $\mathrm{CHF}, \mathrm{n}(\%)$ & $16(11.9)$ & $4(28.6)$ & 0.097 \\
\hline COPD, n (\%) & $23(17.0)$ & $4(28.6)$ & 0.284 \\
\hline MVR, n (\%) & $9(6.7)$ & $1(7.1)$ & 1.000 \\
\hline AVR, n (\%) & $14(10.4)$ & $3(21.4)$ & 0.202 \\
\hline Tricuspid anuloplasty, n (\%) & $6(4.4)$ & $1(7.1)$ & 0.506 \\
\hline $\begin{array}{l}\text { Medical treatment } \\
\text { Acetylsalicylic acid, n (\%) } \\
\text { Clopidogrel, n (\%) } \\
\text { Beta-blocker, n (\%) } \\
\text { Ca channel blocker, n (\%) } \\
\text { Statin, n (\%) } \\
\text { Ace inhibitor/ARB, n (\%) } \\
\text { Warfarin, n (\%) }\end{array}$ & $\begin{array}{l}49(36.3) \\
26(19.3) \\
49(36.3) \\
22(16.7) \\
31(23.0) \\
45(33.3) \\
23(17.0)\end{array}$ & $\begin{array}{l}5(35.7) \\
4(28.6) \\
6(42.9) \\
4(28.6) \\
5(35.7) \\
7(50.0) \\
5(35.7)\end{array}$ & $\begin{array}{l}0.966 \\
0.482 \\
0.631 \\
0.276 \\
0.327 \\
0.245 \\
0.141 \\
\end{array}$ \\
\hline
\end{tabular}

Continuous variables are presented as mean \pm SD or median, nominal variables are presented as frequency (\%). Abbreviations: $\mathrm{PCl}$, percutaneous coronary intervention CABG, coronary artery bypass graft; CVA, cerebrovascular accident; CRF, chronic renal failure; $\mathrm{CHF}$, congestive heart failure; COPD, chronic obstructive pulmonary disease; MVR, mitral valve replacement; AVR, aortic valve replacement.

had a sensitivity of $71.4 \%$ and a specificity of $63 \%$ to predict LAT.

\section{DISCUSSION}

In AIS patients, $\mathrm{AF}$ is the most well-defined risk factor for cardio-embolism. However, a prior case-control TEE-based study showed that the thrombus formation might occur in subjects with sinus rhythm due to the impairment of the flow velocities in the $\mathrm{LAA}^{6}$. In this study, Agmon et al. ${ }^{6}$ reported that sinus rhythm was present in 20 patients (6.3\%) out of 314 with LAT during TEE evaluation. Additionally, Karabay et al. ${ }^{7}$ investigated LA deformations using speckle tracking echocardiography to predict LAT in patients with suspected cardioembolic stroke who had normal sinus rhythm. They found that the frequency of LAT in AIS patients without AF was $6.2 \%$ (9 out of 144 patients). In our study, the frequency of LAT was 9.3\% (14 out of 149 patients), which was slightly higher.

\section{FIGURE 2.}

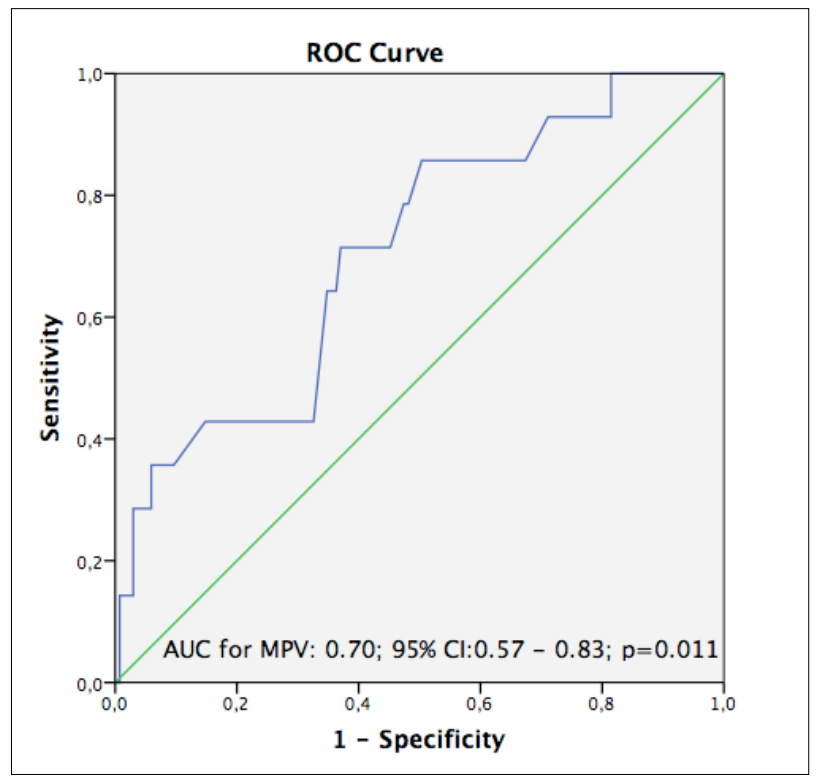

A number of recent studies have demonstrated that the left ventricle EF is strongly correlated with the formation of LAT in patients with AF undergoing TEE examination. Ayirala et al. ${ }^{8}$ performed a case-control study in 334 consecutive patients with AF who had undergone TEE examination for the presence of LAT. In their multivariate analysis, left ventricle EF was found to be an independent predictor of LAT. Moreover, Rader et al. ${ }^{9}$ found that solely left ventricle $\mathrm{EF}<40 \%$ was an independent predictor of LAT in 524 patients with AF who underwent TEE. Although our data were consistent with the findings of those published case-control studies, we were also able to demonstrate that left ventricle EF was an independent predictor of LAT in AIS patients without AF in our study. As a possible explanation of this finding, we considered that patients with low ventricle EF had usually hypercoagulable status due to increased platelet activation and elevation of coagulation parameters such as thromboglobulin and thrombin-antithrombin III, which might cause thrombus formation ${ }^{10}$.

The second important predictor of LAT in our study was the presence of low LAA peak emptying velocity. We thought that the presence of LAA dysfunction in such patients may play a key role in the formation of LAT. Besides that, atrial cardiopathy, which might cause a reduced LAA peak emptying velocity, might be another potential cause of cardio-embolism among the groups of patients with AIS in the study ${ }^{\mathbf{1 1}}$. Based on their results, Yaghi et al. ${ }^{11}$ have suggested that a reduced LAA peak flow velocity might be correlated 
TABLE 2. COMPARISON OF LABORATORY AND ECHOCARDIOGRAPHY PARAMETERS OF PATIENTS ACCORDING TO THE PRESENCE OF THROMBUS

\begin{tabular}{|c|c|c|c|}
\hline & $\begin{array}{l}\text { Thrombus (-) } \\
(n=135)\end{array}$ & $\begin{array}{l}\text { Thrombus }(+) \\
(n=14)\end{array}$ & $\begin{array}{l}P \\
\text { value }\end{array}$ \\
\hline \multicolumn{4}{|l|}{ Laboratory variables } \\
\hline Hematocrit, (\%) & $38.0(33.4-43.0)$ & $36.7(33.0-41.0)$ & 0.530 \\
\hline Hemoglobin, g/dL & $12.5(10.9-14.4)$ & $11.7(10.3-13.9)$ & 0.273 \\
\hline Red blood cell distribution width, $\%$ & $14.7(12.5-14.8)$ & $15.5(14.5-15.9)$ & 0.003 \\
\hline WBC, cells/ $\mu \mathrm{L}$ & $8.0(6.0-9.6)$ & $8.5(7.0-10.0)$ & 0.513 \\
\hline Platelet count, $\mathrm{mm}^{3}$ & $245.0(192.0-284.0)$ & $217.9(126.0-323.0)$ & 0.350 \\
\hline MPV,fL & $8.8(7.5-10.4)$ & $11.0(9.5-12.1)$ & 0.001 \\
\hline Plateletcrit, \% & $1.24(0.88-1.25)$ & $1.81(1.04-2.54)$ & 0.743 \\
\hline Creatinine, $\mathrm{mg} / \mathrm{dL}$ & $1.23(0.88-1.22)$ & $1.78(1.10-2.50)$ & 0.001 \\
\hline BUN, mg/dL & $41.2(26.0-49.0)$ & $58.4(40.0-72.0)$ & 0.004 \\
\hline $\mathrm{TSH}, \mathrm{U} / \mathrm{L}$ & $2.13(0.60-1.83)$ & $1.67(0.50-2.61)$ & 0.996 \\
\hline $\mathrm{T} 4, \mathrm{U} / \mathrm{L}$ & $1.03(0.93-1.12)$ & $1.06(0.91-1.21)$ & 0.516 \\
\hline AST, U/L & $27.2(18.0-31.0)$ & $26.4(16.0-23.0)$ & 0.165 \\
\hline $\mathrm{ALT}, \mathrm{U} / \mathrm{L}$ & $28.1(15.0-34.0)$ & $27.2(11.0-34.0)$ & 0.220 \\
\hline INR & $1.57(1.10-1.80)$ & $1.85(1.25-2.33)$ & 0.050 \\
\hline Glucose, mg/dl & $111.1(85.0-120.0)$ & $111.4(96.5-121.5)$ & 0.425 \\
\hline C-reactive protein, $\mathrm{mg} / \mathrm{dL}$ & $27.4(2.00-24.00)$ & $37.4(2.30-46.40)$ & 0.233 \\
\hline \multicolumn{4}{|l|}{ Echocardiography variables } \\
\hline Ejection fraction, \% & $53.4(50.0-60.0)$ & $39.6(30.0-45.0)$ & $<0.001$ \\
\hline LA anterior-posterior diameter, mm & $42.0(36.0-48.5)$ & $45.2(40.0-48.0)$ & 0.204 \\
\hline LVEDD, $\mathrm{mm}$ & $49.1(46.0-53.0)$ & $52.3(45.0-59.0)$ & 0.211 \\
\hline LVESD, mm & $36.2(32.0-41.0)$ & $38.6(33.0-45.0)$ & 0.299 \\
\hline$M R \geq+3, n(\%)$ & $23(17.0)$ & $2(14.3)$ & 1.000 \\
\hline $\mathrm{TR} \geq+3, \mathrm{n}(\%)$ & $17(12.6)$ & $5(35.7)$ & 0.036 \\
\hline$A R \geq+3, n(\%)$ & $9(6.7)$ & $2(14.3)$ & 0.276 \\
\hline$A S \geq+3, n(\%)$ & $7(5.2)$ & $0(0.0)$ & 1.000 \\
\hline PASP, $\mathrm{mm} \mathrm{Hg}$ & $39.0(35.0-45.0)$ & $40.5(30.0-50.0)$ & 0.321 \\
\hline PFO, n (\%) & $28(20.7)$ & $2(14.3)$ & 0.435 \\
\hline Interatrial aneurysm, n (\%) & $14(10.4)$ & $3(21.4)$ & 0.202 \\
\hline LAA peak emptying velocity, $\mathrm{cm} / \mathrm{s}$ & $47.9(36.0-62.0)$ & $31.9(20.0-38.0)$ & 0.001 \\
\hline
\end{tabular}

Continuous variables are presented as mean \pm SD or median, nominal variables are presented as frequency (\%). Abbreviations: WBC, white blood cell; MPV, mean platelet volume; BUN, blood urea nitrogen; TSH, thyroid-stimulating hormone; AST, aspartate aminotransferase; ALT; alanine aminotransferase; LA, left atrium; LVEDD, left ventricular end-diastolic diameter; LVESD, left ventricular end-systolic diameter; MR, mitral regurgitation; TR, tricuspid regurgitation; AR, aortic regurgitation; AS, aortic stenosis; PASP, pulmonary artery systolic pressure; PFO, patent foramen ovale; LAA, left atrial appendix.

TABLE 3. UNIVARIATE AND MULTIVARIATE LOGISTIC REGRESSION ANALYSIS FOR THE PREDICTORS OF LEFT ATRIUM THROMBUS*

\begin{tabular}{|c|c|c|c|c|}
\hline & \multicolumn{2}{|c|}{ Univariate analysis } & \multicolumn{2}{|c|}{ Multivariate analysis } \\
\hline & $P$ value & OR $(95 \% \mathrm{Cl})$ & P value & OR $(95 \% \mathrm{Cl})$ \\
\hline Age & 0.011 & $1.063(1.014-1.114)$ & - & - \\
\hline MPV & $<0.001$ & $1.942(1.351-2.793)$ & 0.007 & $0.827(0.723-0.947)$ \\
\hline Creatinine & 0.026 & $1.729(1.066-2.804)$ & 0.014 & $2.649(1.219-5.755)$ \\
\hline BUN & 0.027 & $1.021(1.002-1.040)$ & - & - \\
\hline Ejection fraction & $<0.001$ & $0.807(0.716-0.910)$ & 0.006 & $1.874(1.184-2.966)$ \\
\hline LAA peak emptying velocity & 0.008 & $0.922(0.869-0.979)$ & 0.043 & $0.939(0.884-0.998)$ \\
\hline
\end{tabular}

*Binary logistic regression analyses using the backward LR method for multivariate analysis of the independent variables that were included if they were significantly different in univariate analyses $(p<0.05)$. OR: Odds ratio, Cl: Confidence interval. Abbreviations: MPV, mean platelet volume; LAA, left atrial appendage.

with cardio-embolic risk in patients with cryptogenic stroke.

In our study, we also observed that MPV was another important predictor of LAT among these patients. MPV, which indicates platelet size, is useful to predict platelet function and activity. In an experimental study, it has been demonstrated that platelets with larger size show greater aggregation and release more thromboxane A2 and beta-thromboglobulin than smaller ones, which in turn result 
in high prothrombotic potential ${ }^{12}$. In a single-center study that included 427 consecutive AF patients who had undergone TEE examination for the exclusion of LAT before cardioversion, Providência et al..$^{13}$ showed that elevated MPV was related to the presence of left atrial stasis in patients with non-valvular AF. In addition to this study, Turfan et al. ${ }^{14}$ have found that AF patients with AIS might have higher MPV compared to those without stroke due to a high risk of cardio-embolism. Besides, in a systematic review and meta-analysis conducted by Chu et al. ${ }^{15}$, it was shown that elevated MPV might have a potential link with acute myocardial infarction and restenosis following percutaneous coronary intervention. However, to our knowledge, there are no previous studies regarding the relationship between elevated MPV and LAT in AIS patients with sinus rhythm. This research, therefore, may provide novel information with respect to the applicability of MPV to predict LAT in AIS patients without AF.

We considered that our findings may be useful in terms of clinical applicability. A risk stratification system that enables identifying the patients who would require further TEE examination could be performed based on our study results. Particularly, AIS patients with sinus rhythm who had low left ventricle EF on TTE, higher creatinine value, and elevated MPV represented a high-risk group for LAT. Therefore, these patients should undergo further TEE examination to verify the possibility of a cardio-embolic source.

\section{Study limitations}

The present study has the following limitations: first, it was conducted in a single center with a limited number of patients. Second, the major limitation was the retrospective design, which might include selection bias. However, we tried to enroll all consecutive patients. Third, even though some parameters such as D-dimer, fibrinogen, and brain natriuretic peptide were shown to be related with thrombus formation in previous studies, we could not assess these parameters due to missing data. Finally, prospective, multicenter, randomized studies are needed to confirm our results.

\section{CONCLUSION}

Based on our study findings, low ventricle EF and elevated MPV were significant predictors for the presence of LAT in AIS patients without AF. Hence, in addition to a TTE evaluation and Holter monitoring, these patients should undergo further TEE examination to verify the possibility of a cardio-embolic source.

\section{Conflict of interest}

The authors have no conflicts of interest relevant for this article

\section{Funding}

The authors declare that this article has received no financial support.

\section{Author's Contribution}

Concept: T.Ç. Design: T.Ç., V.Ç., M.İ.H. Supervision: N.K., A.L.O., M.M.A. Funding: M.M.A., V.Ç., N.K. Material: V.Ç., M.M.A. Data collection: V.Ç., T.Ç. Analysis: M.İ.H. Literature review: V.Ç., M.M.A. Writing: T.Ç. Critical review: N.K., A.L.O.

\section{RESUMO}

INTRODUÇÃO: O presente estudo teve como objetivo determinar indicadores independentes do trombo auricular esquerdo (LAT) em doentes com acidente vascular cerebral isquêmico agudo (AIS) sem fibrilação auricular (AF) utilizando ecocardiografia transesofágica (TEE).

MÉTODOS: Neste único centro, estudo retrospectivo, inscrevemos 149 pacientes consecutivos com AIS. Todos os pacientes foram submetidos a exame de TEE para detectar LAT no prazo de dez dias após a admissão. A análise de regressão logística multivariada foi realizada para avaliar preditores independentes do final.

RESULTADO: Entre todos os casos, 14 pacientes (9,3\%) tiveram um diagnóstico de exame tardio no TEE. Numa análise multivariada, volume médio de plaquetas (VMP) elevado, fração de ejeção do ventrículo esquerdo baixo (EF), creatinina e uma velocidade de pico de esvaziamento do átrio esquerdo reduzida (LAA) foram indicadores independentes da LAT. A área sob a análise da curva característica de operação do receptor para VMP foi de 0,70 (95\% IC: 0, 57-0, 83; $p=0,011$ ). Com o valor-limite ideal de 9,45, o VMP teve uma sensibilidade de $71,4 \%$ e uma especificidade de $63 \%$ para prever mais tarde.

CONCLUSÃO: Os doentes AIS com EF ventricular baixa e VMP elevado devem ser submetidos a um exame de TEE adicional para determinar a possibilidade de origem cardioembólica. Além disso, esta investigação pode fornecer novas informações sobre a aplicabilidade do VMP para prever tardiamente os doentes sem AF.

PALAVRAS-CHAVE: Acidente vascular cerebral. Átrios do coração. Trombose. Volume plaquetário médio. 


\section{REFERENCES}

1. Donkor ES. Stroke in the $21^{\text {st }}$ century: a snapshot of the burden, epidemiology, and quality of life. Stroke Res Treat. 2018;2018:3238165.

2. Adams HP Jr, Bendixen BH, Kappelle LJ, Biller J, Love BB, Gordon DL, et al. Classification of subtype of acute ischemic stroke. Definitions for use in a multicenter clinical trial. TOAST. Trial of Org 10172 in Acute Stroke Treatment. Stroke. 1993;24(1):35-41.

3. Arboix A, Alió J. Cardioembolic stroke: clinical features, specific cardiac disorders and prognosis. Curr Cardiol Rev. 2010;6(3):150-61.

4. Saric M, Armour AC, Arnaout MS, Chaudhry FA, Grimm RA, Kronzon I, et al. Guidelines for the use of echocardiography in the evaluation of a cardiac source of embolism. J Am Soc Echocardiogr. 2016;29(1):1-42.

5. Grysiewicz RA, Thomas K, Pandey DK. Epidemiology of ischemic and hemorrhagic stroke: incidence, prevalence, mortality, and risk factors. Neurol Clin. 2008;26(4):871-95.

6. Agmon Y, Khandheria BK, Gentile F, Seward JB. Clinical and echocardiographic characteristics of patients with left atrial thrombus and sinus rhythm: experience in 20643 consecutive transesophageal echocardiographic examinations. Circulation. 2002;105(1):27-31.

7. Karabay CY, Zehir R, Güler A, Oduncu V, Kalayci A, Aung SM, et al. Left atrial deformation parameters predict left atrial appendage function and thrombus in patients in sinus rhythm with suspected cardioembolic stroke: a speckle tracking and transesophageal echocardiography study. Echocardiography. 2013;30(5):572-81.
8. Ayirala S, Kumar S, O'Sullivan DM, Silverman DI. Echocardiographic predictors of left atrial appendage thrombus formation. J Am Soc Echocardiogr. 2011;24(5):499-505

9. Rader V|, Khumri TM, Idupulapati M, Stoner CN, Magalski A, Main ML Clinical predictors of left atrial thrombus and spontaneous echocardiographic contrast in patients with atrial fibrillation. I Am Soc Echocardiogr. 2007;20(10):1181-5.

10. Snowden S, Silus L. Oral anticoagulation with warfarin for patients with left ventricular systolic dysfunction. Cardiol Rev. 2011;19(1):36-40.

11. Yaghi S, Kamel H, Elkind MSV. Atrial cardiopathy: a mechanism of cryptogenic stroke. Expert Rev Cardiovasc Ther. 2017;15(8):591-9.

12. Machin SJ, Briggs C. Mean platelet volume: a quick, easy determinant of thrombotic risk? J Thromb Haemost. 2010;8(1):146-7.

13. Providência R, Faustino A, Paiva L, Fernandes A, Barra S, Pimenta J, et al. Mean platelet volume is associated with the presence of left atrial stasis in patients with non-valvular atrial fibrillation. BMC Cardiovasc Disord. 2013;13:40.

14. Turfan M, Erdogan E, Ertas G, Duran M, Murat SN, Celik E, et al. Usefulness of mean platelet volume for predicting stroke risk in atrial fibrillation patients. Blood Coagul Fibrinolysis. 2013;24(1):55-8.

15. Chu SG, Becker RC, Berger PB, Bhatt DL, Eikelboom JW, Konkle B, et al. Mean platelet volume as a predictor of cardiovascular risk: a systematic review and meta-analysis. J Thromb Haemost. 2010;8(1):148-56. 